\title{
Active Rehabilitation During Extracorporeal Membrane Oxygenation as a Bridge to Lung Transplantation
}

\author{
Kyle J Rehder MD, David A Turner MD, Matthew G Hartwig MD, W Lee Williford RRT, \\ Desiree Bonadonna CCP LP, Richard J Walczak Jr CCP, R Duane Davis MD, \\ David Zaas MD, and Ira M Cheifetz MD FAARC
}

\begin{abstract}
BACKGROUND: Patients with end-stage lung disease often progress to critical illness, which dramatically reduces their chance of survival following lung transplantation. Pre-transplant deconditioning has a significant impact on outcomes for all lung transplant patients, and is likely a major contributor to increased mortality in critically ill lung transplant recipients. The aim of this report is to describe a series of patients bridged to lung transplant with extracorporeal membrane oxygenation (ECMO) and to examine the potential impact of active rehabilitation and ambulation during pre-transplant ECMO. METHODS: This retrospective case series reviews all patients bridged to lung transplantation with ECMO at a single tertiary care lung transplant center. Pre-transplant ECMO patients receiving active rehabilitation and ambulation were compared to those patients who were bridged with ECMO but did not receive pre-transplant rehabilitation. RESULTS: Nine consecutive subjects between April 2007 and May 2012 were identified for inclusion. One-year survival for all subjects was $100 \%$, with one subject alive at 4 months post-transplant. The 5 subjects participating in pre-transplant rehabilitation had shorter mean post-transplant mechanical ventilation (4 d vs $34 \mathrm{~d}, P=.01$ ), ICU stay (11 d vs $45 \mathrm{~d}, P=.01$ ), and hospital stay ( $26 \mathrm{~d}$ vs $80 \mathrm{~d}$, $P=.01)$. No subject who participated in active rehabilitation had post-transplant myopathy, compared to 3 of 4 subjects who did not participate in pre-transplant rehabilitation on ECMO. CONCLUSIONS: Bridging selected critically ill patients to transplant with ECMO is a viable treatment option, and active participation in physical therapy, including ambulation, may provide a more rapid post-transplantation recovery. This innovative strategy requires further study to fully evaluate potential benefits and risks. Key words: extracorporeal membrane oxygenation; ECMO; lung transplant; rehabilitation; cystic fibrosis; respiratory failure; mechanical ventilation; hypoxia; hypercapnia; acute lung injury. [Respir Care 2013;58(8):1291-1298. (C) 2013 Daedalus Enterprises]
\end{abstract}

\section{Introduction}

Over the past 10 years the number of lung transplants performed on an annual basis has consistently risen, with

Drs Rehder, Turner, and Cheifetz are affiliated with the Division of Pediatric Critical Care Medicine, Department of Pediatrics, Duke Children's Hospital, Durham, North Carolina. Drs Hartwig and Davis are affiliated with the Division of Cardiovascular and Thoracic Surgery, Department of Surgery; Mr Williford and Dr Cheifetz are affiliated with Respiratory Care Services; Ms Bonadonna and Mr Walczak are affiliated with Perfusion Services; and Dr Zaas is affiliated with the Division of Pulmonary, Allergy, and Critical Care Medicine, Department of Internal Medicine, Duke University Medical Center, Durham, North Carolina.

Drs Rehder and Turner are co-first authors. over 3,200 patients transplanted in 2009, at over 125 international centers. ${ }^{1}$ Pre-transplant conditioning is an

\footnotetext{
The authors have disclosed no conflicts of interest.

Dr Rehder presented a version of this paper at the American College of Chest Physicians International Scientific Assembly, held October 20-25, 2012, in Atlanta, Georgia, and at the annual conference of the Extracorporeal Life Support Organization, held September 14-16, 2012, in Seattle, Washington.
}

Correspondence: Kyle J Rehder MD, Division of Pediatric Critical Care, Duke University Medical Center, Box 3046, Durham NC 27710. E-mail: kyle.rehder@duke.edu.

DOI: $10.4187 /$ respcare. 02155 
important predictor of morbidity and mortality in these patients, ${ }^{2,3}$ and almost all centers require lung transplant candidates to participate in pulmonary rehabilitation prior to transplant. Patients must have a degree of illness that warrants listing and lung transplantation; however, deteriorating clinical status prior to transplantation may significantly decrease the likelihood of transplant success and survival. ${ }^{1,4,5}$

The subset of patients who become critically ill and require mechanical ventilation prior to lung transplantation have significantly lower survival, with a decrease in overall 1 year survival rate from $80 \%$ to $63.7 \% .^{1}$ The relative risk of death in patients requiring life support pretransplantation is 1.57 (95\% CI 1.31-1.88) in the year following transplant, when compared to those patients who do not require pre-operative life support. ${ }^{1}$ Mortality is even higher in critically ill patients who continue to deteriorate and require extracorporeal membrane oxygenation (ECMO) prior to transplantation. ${ }^{5-8}$ As reported outcomes in patients supported pre-transplantation with ECMO are poor, the use of ECMO as a bridge to lung transplantation has been quite limited. ${ }^{1,4,8-11}$

\section{See the Related Editorial on Page 1388}

Mortality in transplant patients supported with ECMO is often related to the degree of organ dysfunction, but an important additional contributor is pre-transplant deconditioning. ${ }^{2,3}$ This deconditioning, while commonplace in critically ill patients, is often further exacerbated in those patients who require ECMO secondary to cannulation techniques, immobility, and sedation practices. ${ }^{12}$ Recently published data by Fuehner et al demonstrated improved survival in patients bridged to lung transplant with an "awake ECMO" strategy, when compared to those managed with conventional mechanical ventilation, ${ }^{13}$ showing the potential advantages of minimizing sedation. Beyond minimizing sedation, aggressive early rehabilitation is the next step to potentially further improve outcomes in patients being supported with ECMO as a bridge to lung transplantation. ${ }^{14-16}$ This early conditioning is now possible with the introduction of double lumen veno-venous ECMO cannulae and the increasing portability of ECMO technology. ${ }^{14,17-20}$

The safety of rehabilitation on ECMO has now been reported by several centers. ${ }^{15,16,21,22}$ While early rehabilitation has been demonstrated to improve outcomes in the setting of critical illness, ${ }^{12,23-26}$ the impact of rehabilitation of patients supported with ECMO pre-transplant is unclear. In this report we describe the impact of increased activity and ambulation on patients supported with ECMO as a bridge to lung transplantation.

\section{QUICK LOOK}

\section{Current knowledge}

Patients with end-stage lung disease often progress to critical illness, dramatically reducing survival following lung transplant. Pre-transplant deconditioning negatively impacts outcomes in lung transplant patients.

\section{What this paper contributes to our knowledge}

Bridging selected critically ill patients to transplant with extracorporeal membrane oxygenation (ECMO) is a viable treatment option, and physical therapy, including ambulation, may hasten post-transplantation recovery.

\section{Methods}

With institutional review board approval, we retrospectively identified all patients who received a lung transplant after bridging support with ECMO at Duke University Medical Center. The medical records of these subjects were reviewed with attention to demographics, underlying comorbidities, hospital course, mechanical ventilation modes and strategies, laboratory values, adjunctive therapies, ECMO course and complications, transplant details, and outcomes, including stay, health status at discharge, and 1-year survival. ECMO subjects who received active rehabilitation and ambulation were compared to those subjects who were bridged with ECMO but did not receive pre-transplant rehabilitation. Data between cohorts were compared using the Wilcoxon rank sums test. $P$ values $<.05$ were considered significant.

Our rehabilitation protocol has been previously described by Turner et al. ${ }^{16}$ In brief, rehabilitation began with resistance and stretching exercises, then progressed to sitting, standing, and, ultimately, ambulation. Sessions occurred twice per day, as tolerated by the subject. Staffing during these sessions generally consisted of an ECMO specialist, a respiratory therapist, 2 physical therapists, and 1-2 bedside nurses. Each provider was assigned a specific role, to ensure safety, including one provider dedicated to support and monitor ECMO cannula position.

\section{Results}

We identified 9 consecutive subjects who were bridged to lung transplant with ECMO, all between April 2007 and May 2012. Subjects receiving rehabilitation during ECMO were transplanted between January 2010 and May 2012.

\section{Pre-transplant Health Status}

Table 1 summarizes key demographic features of the 9 transplant recipients included in this study. Primary diag- 


\section{Active Rehabilitation During Extracorporeal Membrane Oxygenation}

Table 1. Subject Demographics

\begin{tabular}{|c|c|c|c|c|c|c|c|c|c|}
\hline Subject & 1 & 2 & 3 & 4 & 5 & 6 & 7 & 8 & 9 \\
\hline Age, y & 55 & 51 & 57 & 17 & 16 & 24 & 58 & 20 & 22 \\
\hline Sex & M & $\mathrm{F}$ & M & $\mathrm{F}$ & $\mathrm{F}$ & $\mathrm{F}$ & M & $\mathrm{F}$ & $\mathrm{F}$ \\
\hline $\begin{array}{l}\text { BMI on admission, } \\
\mathrm{kg} / \mathrm{m}^{2}\end{array}$ & 23.7 & 29.9 & 26.6 & 15.9 & 16.3 & 15.5 & 30.3 & 19.3 & 15.8 \\
\hline Primary diagnosis & $\begin{array}{l}\text { Interstitial } \\
\text { pulmonary } \\
\text { fibrosis }\end{array}$ & $\begin{array}{l}\text { Usual interstitial } \\
\text { pneumonia }\end{array}$ & $\begin{array}{l}\text { Fibrosing non- } \\
\text { specific } \\
\text { interstitial } \\
\text { pneumonia }\end{array}$ & Cystic fibrosis & Cystic fibrosis & Cystic fibrosis & $\begin{array}{l}\text { Interstitial } \\
\text { pulmonary } \\
\text { fibrosis }\end{array}$ & Cystic fibrosis & Cystic fibrosis \\
\hline Secondary diagnoses & Diabetes mellitus & $\begin{array}{l}\text { Dermatomyositis, } \\
\text { hypothyroidism }\end{array}$ & $\begin{array}{l}\text { Mixed connective } \\
\text { tissue disorder, } \\
\text { gastroesophageal } \\
\text { reflux disease }\end{array}$ & $\begin{array}{l}\text { Malnutrition, iron } \\
\text { deficiency } \\
\text { anemia, diabetes } \\
\text { mellitus }\end{array}$ & $\begin{array}{l}\text { Pneumonia, } \\
\text { diabetes } \\
\text { mellitus, } \\
\text { pan-sinusitis }\end{array}$ & $\begin{array}{l}\text { Pneumonia, } \\
\text { Burkholderia } \\
\text { cepacia } \\
\text { bacteremia, } \\
\text { severe } \\
\text { deconditioning, } \\
\text { COPD, diabetes } \\
\text { mellitus, pan- } \\
\text { sinusitis }\end{array}$ & $\begin{array}{l}\text { Dyslipidemia, } \\
\text { hypertension, } \\
\text { alcohol abuse, } \\
\text { gout, chronic } \\
\text { herpes simplex } \\
\text { virus infection } \\
\end{array}$ & $\begin{array}{l}\text { Influenza A, } \\
\text { Alcaligenes } \\
\text { bacteremia, } \\
\text { hypothyroidism, } \\
\text { diabetes mellitus }\end{array}$ & $\begin{array}{l}\text { Malnutrition, } \\
\text { diabetes mellitus }\end{array}$ \\
\hline APACHE III score & 68 & 65 & 51 & 47 & 116 & 97 & 64 & 111 & 44 \\
\hline
\end{tabular}

noses were typical of other patients requiring lung transplantation. Mean age (45 y vs $28 \mathrm{y}, P=.50$ ) and Acute Physiology and Chronic Health Evaluation III score (57.8 vs $86.4, P=.30$ ) were not statistically different between the control cohort (subjects 1-4) and the rehabilitation cohort (subjects 5-9). Subjects 6, 7, and 8 required highfrequency ventilation prior to ECMO cannulation, while subjects 6,8 , and 9 demonstrated systemic inflammatory response physiology at the time of ECMO cannulation.

\section{ECMO and Respiratory Support}

All subjects were bridged to transplant with venovenous ECMO, and all were managed in either the cardiothoracic ICU or pediatric ICU during their ECMO course. Subjects in the control cohort were cannulated using a dual cannula technique, using one cannula for venous drainage to the pump and a second cannula for return of oxygenated blood to the subject. Each subject required at least one femoral vein cannulation, with a second cannula in either the right internal jugular vein or the other femoral vein. ECMO for these subjects utilized the Sorin SCP centrifugal pump (Sorin Groups, Arvada, Colorado) with an oxygenator (Safeline Quadrox D, Maquet, Wayne, New Jersey). Subjects in the rehabilitation cohort were all cannulated percutaneously via the right internal jugular vein, using a single, newly available, 19-27 French dual lumen cannula (Avalon Laboratories, Rancho Domingo, California), placed with the assistance of either fluoroscopy or transesophageal echocardiography. These subjects were maintained on ECMO with a centrifugal pump (Rotaflow, Maquet, Wayne, New Jersey) and oxygenator (Bioline Quadrox D, Maquet, Wayne, New Jersey).

All 9 subjects were anticoagulated for ECMO using unfractionated heparin, with goal activated clotting times of 160-180 seconds. The activated clotting time goal was lowered to 140-160 seconds for those subjects with tracheostomy or cannula site bleeding (subjects 5 and 9). While the subjects did receive bolus paralytics for procedures (eg, tracheostomy placement), no subjects were maintained on paralytic infusions during their ECMO course. All subjects in the control cohort were maintained on mechanical ventilation and sedation while on ECMO awaiting transplant. No formal sedation protocol was used.

No subject had serious complications from ECMO. Subject 1 was noted to have elevated liver enzymes, which resolved after transplantation. Subject 7 had a right internal jugular hematoma that was deemed clinically unimportant. Other key ECMO characteristics are summarized in Table 2.

Surgical tracheostomies were placed in control cohort subjects within the first 9 days following lung transplantation. In comparison, 4 of the rehabilitation cohort subjects $(5,6,8$, and 9$)$ received percutaneous tracheostomies prior to lung transplantation within the first 30 hours following ECMO cannulation. Heparin infusion was held approximately 2 hours prior to and 2 hours after the procedure for each subject. Subject 5 had moderate superficial bleeding post-procedure, and subject 9 required subsequent cauterization of a thyroid laceration, but no other important complications were noted in any of these 4 subjects post-tracheostomy. Subjects 5 and 8 were weaned to humidified oxygen delivered by tracheostomy collar prior to ambulation, while subjects 6 and 9 ambulated while connected to a transport ventilator (Vela, Avea/CareFusion, San Diego, California) on pressure support ventilation, with pressure support of 16-18 $\mathrm{cm} \mathrm{H}_{2} \mathrm{O}$, PEEP of 6$10 \mathrm{~cm} \mathrm{H} \mathrm{H}_{2} \mathrm{O}$, and $\mathrm{F}_{\mathrm{IO}_{2}}$ of $0.4-0.5$. Subject 7 was extubated on ECMO to noninvasive ventilation (BiPAP Vision, Philips Respironics, Murrysville, Pennsylvania) with inspiratory pressure of $12 \mathrm{~cm} \mathrm{H}_{2} \mathrm{O}$, expiratory pressure of 
Active Rehabilitation During Extracorporeal Membrane Oxygenation

Table 2. ECMO Characteristics

\begin{tabular}{|c|c|c|c|c|c|c|c|c|c|}
\hline Subject & 1 & 2 & 3 & 4 & 5 & 6 & 7 & 8 & 9 \\
\hline Pre-ECMO $\mathrm{P}_{\mathrm{aO}_{2}} / \mathrm{F}_{\mathrm{IO}_{2}}$ & 32 & 90 & 71 & 76 & 103 & 69 & 145 & 69 & 124 \\
\hline Pre-ECMO ventilation days & 0.5 & 1 & 0.8 & 0.4 & 7 & 3 & 2 & 1 & 1 \\
\hline Pre-transplant ECMO days & 5 & 1 & 0.5 & 1 & 8 & 7 & 3 & 14 & 11 \\
\hline \multicolumn{10}{|l|}{$\begin{array}{l}\text { Approximate ECMO "rest" } \\
\text { ventilator settings }\end{array}$} \\
\hline Mode & $\begin{array}{l}\text { Continuous mandatory } \\
\text { ventilation }\end{array}$ & $\begin{array}{l}\text { Continuous mandatory } \\
\text { ventilation }\end{array}$ & $\begin{array}{l}\text { Continuous mandatory } \\
\text { ventilation }\end{array}$ & $\begin{array}{l}\text { Continuous mandatory } \\
\text { ventilation }\end{array}$ & $\begin{array}{l}\text { Tracheostomy } \\
\text { collar }\end{array}$ & Support & $\begin{array}{l}\text { Bi-level positive } \\
\text { airway } \\
\text { pressure }\end{array}$ & $\begin{array}{l}\text { Tracheostomy } \\
\text { collar }\end{array}$ & Mixed \\
\hline Limit & Pressure & Pressure & Pressure & Pressure & ND & Pressure & Pressure & ND & Pressure \\
\hline PIP & 30 & 18 & 18 & 36 & ND & 18 & 20 & ND & 23 \\
\hline PEEP & 10 & 8 & 8 & 10 & ND & 6 & 8 & ND & 10 \\
\hline $\mathrm{F}_{\mathrm{IO}_{2}}$ & 0.4 & 0.21 & 0.21 & 1.0 & 1.0 & 0.4 & 0.6 & 1.0 & 0.5 \\
\hline $\begin{array}{l}\text { Typical sedation infusions } \\
\text { while on ECMO }\end{array}$ & $\begin{array}{l}\text { Fentanyl } 50 \mu \mathrm{g} / \mathrm{h} \\
\text { Midazolam } 2 \mathrm{mg} / \mathrm{h} \\
\text { Dexmetomidate } \\
0.5 \mu \mathrm{g} / \mathrm{kg} / \mathrm{h}\end{array}$ & $\begin{array}{l}\text { Fentanyl } 50 \mu \mathrm{g} / \mathrm{h} \\
\text { Lorazepam } 2 \mathrm{mg} / \mathrm{h} \\
\text { Propofol } 40 \mu \mathrm{g} / \mathrm{kg} / \\
\quad \text { min }\end{array}$ & $\begin{array}{l}\text { Fentanyl } 150 \mu \mathrm{g} / \mathrm{h} \\
\text { Propofol } 50 \mu \mathrm{g} / \mathrm{kg} / \\
\text { min }\end{array}$ & $\begin{array}{l}\text { Fentanyl } 100 \mu \mathrm{g} / \mathrm{h} \\
\text { Midazolam } 2 \mathrm{mg} / \mathrm{h}\end{array}$ & None & None & None & None & None \\
\hline Rehabilitation & No & No & No & No & Yes & Yes & Yes & Yes & Yes \\
\hline \multicolumn{10}{|c|}{$\begin{array}{l}\mathrm{ECMO}=\text { extracorporeal membrane oxygenation } \\
\mathrm{ND}=\text { no data available }\end{array}$} \\
\hline
\end{tabular}

$8 \mathrm{~cm} \mathrm{H}_{2} \mathrm{O}$, and $\mathrm{F}_{\mathrm{IO}_{2}}$ of 0.6 , prior to transplantation, and did not require a tracheostomy pre- or post-transplant.

\section{Rehabilitation}

Nutrition was provided to all subjects via gastrojejunostomy tubes. Subjects in the control cohort were sedated for the duration of their support with mechanical ventilation and ECMO and did not participate in physical therapy or rehabilitation during this time. Following ECMO cannulation and stabilization, sedation was minimized for subjects in the rehabilitation cohort, to allow participation in rehabilitation. Ventilator support was also weaned in these subjects, tolerating oxygen saturations greater than $85 \%$.

All subjects in the rehabilitation cohort began actively participating in physical therapy within 5 days of ECMO cannulation, 3 within the first 48 hours. Four of 5 subjects ambulated on ECMO; subject 8 ambulated approximately $213 \mathrm{~m}$, and subject 9 ambulated over $396 \mathrm{~m}$ in one rehabilitation session. Subject 7 received his transplant early in his ECMO course, after participating in physical therapy (resistance exercises and sitting on edge of bed) but prior to attempted ambulation. On average, subjects receiving rehabilitation received longer courses of mechanical ventilation and ECMO prior to lung transplantation, likely secondary to delayed listing for transplant during the rehabilitation process.

\section{Transplant}

Eight subjects underwent bilateral orthotopic lung transplant. Subject 2 received a lobar transplant, due to size mismatch. All subjects were supported with ECMO for their lung transplantation, with the exception of subject 4, who was transitioned to cardiopulmonary bypass for the procedure, due to surgeon preference. Subject 1 required 4 days of post-transplant ECMO, subjects 2 and 8 were decannulated from ECMO at time of transplant, and all other subjects were removed from ECMO within 24 hours after transplant. Immunosuppressant protocols were the same for all 9 subjects.

\section{Outcomes}

One-year survival for subjects $1-8$ was $100 \%$. Subject 9 was alive at the time of the submission of this paper, at 4 months post-transplant. Post-transplant duration of ventilation, post-transplant ICU stay, post-transplant hospital stay, total ICU stay, and total hospital stay were all shorter for subjects receiving rehabilitation. Key subject outcomes are summarized in Tables 3 and 4. Subject 4 required resection of an infarcted right middle lobe prior to discharge. Subject 3 died at 50 months post-transplant, from colon cancer. Subject 5 required single lung retransplantation for graft failure at 234 days for chronic rejection, and died at 16 months post-initial transplantation. Subject 8 died at 17 months post-transplant, also from complications of chronic rejection.

All subjects were on room air at discharge, and there were no notable differences in 3- or 12-month $\mathrm{FEV}_{1}$ values. No subjects had focal neurologic deficits at discharge; however, subjects 2,3 , and 4 were diagnosed with critical illness neuromyopathy, compared to none of the subjects receiving rehabilitation. Electromyography was performed on any subject with concerns for weakness: electromyography on subject 2 demonstrated a proximal myopathy, subject 3 a proximal myopathy and polyneuropathy, subject 4 a diffuse myopathy, and normal 
Table 3. Individual Subject Outcomes

\begin{tabular}{|c|c|c|c|c|c|c|c|c|c|}
\hline Subject & 1 & 2 & 3 & 4 & 5 & 6 & 7 & 8 & 9 \\
\hline $\mathrm{FEV}_{1}(\%$ predicted $)$ at 3 months ${ }^{27}$ & 44 & $\begin{array}{l}\text { Unable to } \\
\text { perform }\end{array}$ & 25 & 38 & 32 & 36 & 42 & 21 & 43 \\
\hline $\mathrm{FEV}_{1}(\%$ predicted $)$ at 12 months ${ }^{27}$ & 66 & 62 & 43 & 65 & 65 & 70 & 34 & 38 & N/A \\
\hline $\begin{array}{l}\text { Best } \mathrm{FEV}_{1}(\% \text { predicted }) \text { any time } \\
\text { in the first } 12 \text { months }{ }^{27}\end{array}$ & 69 & 63 & 43 & 65 & 65 & 70 & 54 & 53 & 43 \\
\hline Walk distance at discharge, $\mathrm{m}$ & 183 & ND & 457 & 213 & 366 & 549 & 91 & 1,067 & 1,829 \\
\hline Total ICU stay, d & 39 & 49 & 60 & 48 & 23 & 25 & 33 & 22 & 30 \\
\hline Total hospital stay, d & 51 & 102 & 86 & 151 & 53 & 50 & 63 & 31 & 47 \\
\hline Status at data collection & $\begin{array}{l}\text { Alive at } \\
65 \text { months }\end{array}$ & $\begin{array}{l}\text { Died at } \\
50 \text { months }\end{array}$ & $\begin{array}{l}\text { Alive at } \\
54 \text { months }\end{array}$ & $\begin{array}{l}\text { Alive at } \\
47 \text { months }\end{array}$ & $\begin{array}{l}\text { Died at } \\
16 \text { months }\end{array}$ & $\begin{array}{l}\text { Alive at } \\
25 \text { months }\end{array}$ & $\begin{array}{l}\text { Alive at } \\
23 \text { months }\end{array}$ & $\begin{array}{l}\text { Died at } \\
17 \text { months }\end{array}$ & $\begin{array}{l}\text { Alive at } \\
4 \text { months }\end{array}$ \\
\hline
\end{tabular}

$\overline{\mathrm{ND}}=$ no data available

Table 4. Comparison of Outcomes by Cohort

\begin{tabular}{|c|c|c|c|}
\hline & $\begin{array}{l}\text { Control Cohort } \\
\text { mean (range) }\end{array}$ & $\begin{array}{l}\text { Rehabilitation Cohort } \\
\text { mean (range) }\end{array}$ & $P$ \\
\hline $\mathrm{FEV}_{1}(\%$ predicted $)$ at 3 months ${ }^{27}$ & $36(25-44)$ & $35(21-43)$ & .65 \\
\hline $\mathrm{FEV}_{1}(\%$ predicted $)$ at 12 months $^{27}$ & $59(43-66)$ & $52(34-70)$ & .66 \\
\hline Best $\mathrm{FEV}_{1}(\%$ predicted $)$, any time in the first 12 months ${ }^{27}$ & $60(43-69)$ & $57(43-70)$ & .80 \\
\hline Walk distance at discharge, $\mathrm{m}$ & $213(0-457)$ & $780(91-1,829)$ & .14 \\
\hline Total hospital stay, d & $98(51-151)$ & $49(31-63)$ & .05 \\
\hline Total ICU stay, d & $49(39-60)$ & $27(22-33)$ & .01 \\
\hline Days until free of mechanical ventilation for $48 \mathrm{~h}$, post-transplant, $\mathrm{d}$ & $34(22-54)$ & $4(1-11)$ & .01 \\
\hline ICU stay post-transplant, $\mathrm{d}$ & $45(34-56)$ & $11(6-21)$ & .01 \\
\hline Days until tracheostomy removal, post-transplant, $\mathrm{d}$ & $73(44-104)$ & $30(13-46)$ & .04 \\
\hline Hospital stay, post-transplant, d & $80(45-110)$ & $26(13-33)$ & .01 \\
\hline
\end{tabular}

findings for subject 5. Subject 2 was discharged to an in-patient rehabilitation facility, due to her substantial deconditioning, while all other subjects were discharged home with scheduled out-patient rehabilitation.

\section{Discussion}

Critical illness dramatically decreases the likelihood of successful lung transplantation, $, 4,28$ such that support with mechanical ventilation and/or ECMO are relative contraindications to lung transplantation in some centers. ${ }^{29}$ Despite the severity of critical illness in the subjects included in this study, 1 year post-transplant survival was $100 \%$, demonstrating that bridging subjects to lung transplantation with ECMO may be a viable option for selected critically ill patients with end-stage lung disease. While several other studies have shown success using ECMO as a bridge to transplant, $, 9,13,21,30$ this is the first series to show comparison data using a novel rehabilitation and ambulation strategy for these critically ill subjects.

This report has several limitations, most notably, the small sample size and retrospective data collection from a single institution. It is difficult to compare subgroups within this population, because of potential selection bias, confounders, and small numbers. Of note, 4 of 5 rehabilitation subjects had cystic fibrosis as the primary diagnosis, compared to 1 of 4 subjects receiving traditional ECMO. While not statistically different, the rehabilitation subjects also had an apparent younger mean age (28 years vs 45 years), but also had a higher mean Acute Physiology and Chronic Health Evaluation III score (86.4 vs 57.8) and a longer mean pre-transplant ECMO course ( $9 \mathrm{~d}$ vs $2 \mathrm{~d}$ ). As surgical techniques, nutritional support, post-transplant care, immunosuppressant regimens, and other medical management were largely unchanged during this time period, it is feasible the transition to an active rehabilitation approach prior to transplant directly affected the outcome differences seen between these patient groups. The positive effects of pre-transplant conditioning have previously been well documented, with patients receiving lung transplantation after prolonged mechanical ventilation, ${ }^{29,31}$ suggesting that ECMO patients might experience similar benefits. However, given the number of potential confounders and the cohorts coming from different time periods, it should be noted that clear cause and effect is difficult to ascertain in this case series. 
A key consideration in the application of ECMO with rehabilitation as a bridge to lung transplant is patient selection. All subjects in this report had single-organ failure and a limited course of critical illness; however, comorbidities, including diabetes, bacteremia, and malnutrition, were common. The degree of critical illness and organ dysfunction led to the referral of 2 of the rehabilitation cohort patients to our center, after being deemed excessively high-risk by other transplant centers. In each case it was believed that the patient's mortality approached $100 \%$ without initiation of ECMO as a bridge to transplantation. To optimize each patient's lung transplant candidacy, ECMO was initiated as early as possible following intubation, using a single cannulation site to allow for maximal mobility and to minimize deconditioning.

As transplantable organs are a rare and valuable resource, their utilization must be considered carefully. Two subjects in the rehabilitation cohort had bacteremia at the time of ECMO cannulation, and the expectation that infection had to be cleared prior to listing for lung transplant was made clear to the subjects' families prior to ECMO cannulation. Additionally, forthright discussions were held to ensure a clear understanding that listing for lung transplant was contingent upon successful rehabilitation on ECMO.

For the 5 subjects in this study rehabilitated while supported with ECMO, mean time to hospital discharge posttransplant is comparable to the general, non-critically-ill lung transplant population. ${ }^{32,33}$ Post-transplant stay for these subjects was notably shorter than previously reported for subjects supported with mechanical ventilation and/or non-awake ECMO prior to transplantation, ${ }^{6,31,34}$ and potentially shorter than for subjects supported with awake ECMO prior to transplant. ${ }^{13}$ Comparison between the outcomes of our study and the awake ECMO subjects reported by Fuehner et al is difficult, as that study used early application of ECMO prior to mechanical ventilation and associated deconditioning, and did not study the effects of active physical therapy and ambulation on this population. When compared to the non-critically-ill lung transplant population at our center, the rehabilitation cohort had similar duration of mechanical ventilation and ICU stay posttransplant, but slightly extended hospital stay.

Despite having longer pre-transplant mechanical ventilation and ECMO courses, subjects undergoing rehabilitation were better conditioned than the traditionally managed ECMO patients, as evidenced by the lack of neuromyopathy, improved post-transplant ambulation, and shorter time to ICU and hospital discharge. It seems counterintuitive that prolonged duration of life support for critically ill patients awaiting lung transplant could improve outcomes, but this active rehabilitation program represents a paradigm shift in the management of these complex patients. With a small population of subjects it is difficult to determine what effect this conditioning has on longterm outcomes; however, prior studies have shown a clear relationship between short- and long-term outcomes in lung transplant patients. ${ }^{1,32,33,35}$ Presumably, reducing posttransplant ICU and hospital stay will lead to fewer shortterm-complications and improved long-term outcomes.

Numerous safety concerns must be carefully considered before attempting to rehabilitate patients supported with ECMO. ${ }^{14,16,21}$ Using a well coordinated multidisciplinary effort, the subjects in this study had no serious complications related to participating in physical therapy and rehabilitation while supported with ECMO. Several other centers have also reported successful ambulation in patients supported with ECMO, with minimal complications, both as a bridge to lung transplant and for other causes of respiratory failure. ${ }^{14,15,21,22}$

Another important consideration in implementation of a program of this nature is the amount of time spent on the waiting list for transplant. A relatively short wait time on the transplant list may be important for success in these patients, given the potential for increased complications related to the prolonged utilization of ECMO. However, in non-ambulatory ECMO patients, successful lung transplantation has been reported after 107 days of ECMO support. ${ }^{36}$ Each of the subjects in this study received donor lungs within 14 days of being listed for transplant. While this shortened wait time is aided by the level of critical illness, our center's average wait time of 18 days is dramatically shorter than the 150 day average reported for all centers. ${ }^{4}$ As such, the use of ambulatory ECMO as a successful bridge to lung transplant may not be easily generalizable to centers with longer average wait times.

As we continue to develop our ambulatory ECMO program, increased numbers of subjects will provide us with a better understanding of the potential benefits and risks of this approach. There are a number of clear challenges and risks associated with ambulating patients supported by ECMO, but the results of this study add to the growing number of reports supporting the safety of active physical conditioning provided by this novel strategy. Availability of a program of this nature may lead to reconsideration of the lung transplant candidacy of select critically ill patients and also change the overall approach to the management of critical illness in the setting of lung transplantation.

\section{Conclusions}

Bridging critically ill patients to lung transplantation with veno-venous ECMO is a viable treatment option for selected patients. When patients require ECMO support prior to lung transplant, active participation in physical therapy, including ambulation, may provide for a more rapid post-transplantation recovery. 


\section{Active Rehabilitation During Extracorporeal Membrane Oxygenation}

\section{ACKNOWLEDGMENTS}

The extraordinary clinical care described in this paper would not be possible without the tremendous efforts of the multidisciplinary care team, including but not limited to the pediatric and adult critical care physicians, nurses, and respiratory therapists, members of the lung transplant team, transplant surgeons, ECMO specialists, perfusionists, and physical and occupational therapists. We also would like to acknowledge the efforts and perseverance of the rehabilitation patients and their families who participated in the active physical therapy regimens, pre- and post-transplant.

\section{REFERENCES}

1. The International Society for Heart \& Lung Transplantation. 2012 slides. Overall lung and adult lung transplantation statistics. http:// www.ishlt.org/registries/slides.asp?slides=heartLungRegistry. Accessed May 17, 2013.

2. Maury G, Langer D, Verleden G, Dupont L, Gosselink R, Decramer $\mathrm{M}$, et al. Skeletal muscle force and functional exercise tolerance before and after lung transplantation: a cohort study. Am J Transplant 2008;8(6):1275-1281.

3. Reinsma GD, ten Hacken NH, Grevink RG, van der Bij W, Koeter $\mathrm{GH}$, van Weert E. Limiting factors of exercise performance 1 year after lung transplantation. J Heart Lung Transplant 2006;25(11): 1310-1316.

4. US Health \& Human Services. Organ Procurement and Transplantation Network data reports. http://optn.transplant.hrsa.gov/data. Accessed May 17, 2013.

5. Russo MJ, Davies RR, Hong KN, Iribarne A, Kawut S, Bacchetta M, et al. Who is the high-risk recipient? Predicting mortality after lung transplantation using pretransplant risk factors. J Thorac Cardiovasc Surg 2009;138(5):1234-1238 e1231.

6. Hammainen P, Schersten H, Lemstrom K, Riise GC, Kukkonen S, Sward K, et al. Usefulness of extracorporeal membrane oxygenation as a bridge to lung transplantation: a descriptive study. J Heart Lung Transplant 2011;30(1):103-107.

7. Mason DP, Thuita L, Nowicki ER, Murthy SC, Pettersson GB, Blackstone EH. Should lung transplantation be performed for patients on mechanical respiratory support? The US experience. J Thorac Cardiovasc Surg 2010;139(3):765-773 e761.

8. Puri V, Epstein D, Raithel SC, Gandhi SK, Sweet SC, Faro A, et al. Extracorporeal membrane oxygenation in pediatric lung transplantation. J Thorac Cardiovasc Surg 2010;140(2):427-432.

9. Jackson A, Cropper J, Pye R, Junius F, Malouf M, Glanville A. Use of extracorporeal membrane oxygenation as a bridge to primary lung transplant: 3 consecutive, successful cases and a review of the literature. J Heart Lung Transplant 2008;27(3):348-352.

10. Nosotti M, Rosso L, Palleschi A, Lissoni A, Crotti S, Marenghi C, et al. Bridge to lung transplantation by venovenous extracorporeal membrane oxygenation: a lesson learned on the first four cases. Transplant Proc 2010;42(4):1259-1261.

11. Olsson KM, Simon A, Strueber M, Hadem J, Wiesner O, Gottlieb J, et al. Extracorporeal membrane oxygenation in nonintubated patients as bridge to lung transplantation. Am J Transplant 2010; 10(9):2173-2178.

12. Griffiths RD, Hall JB. Intensive care unit-acquired weakness. Crit Care Med 2010;38(3):779-787.

13. Fuehner T, Kuehn C, Hadem J, Wiesner O, Gottlieb J, Tudorache I, et al. Extracorporeal Membrane Oxygenation in Awake Patients as Bridge to Lung Transplantation. Am J Respir Crit Care Med 2012; 185(7):763-768
14. Garcia JP, Kon ZN, Evans C, Wu Z, Iacono AT, McCormick B, et al. Ambulatory veno-venous extracorporeal membrane oxygenation: innovation and pitfalls. J Thorac Cardiovasc Surg 2011;142(4): 755-761.

15. Hayes D, Jr., Kukreja J, Tobias JD, Ballard HO, Hoopes CW. Ambulatory venovenous extracorporeal respiratory support as a bridge for cystic fibrosis patients to emergent lung transplantation. J Cyst Fibros 2012;11(1):40-45.

16. Turner DA, Cheifetz IM, Rehder KJ, Williford WL, Bonadonna D, Banuelos SJ, et al. Active rehabilitation and physical therapy during extracorporeal membrane oxygenation while awaiting lung transplantation-a practical approach. Crit Care Med 2011;39(12):25932598.

17. Bermudez CA, Rocha RV, Zaldonis D, Bhama JK, Crespo MM, Shigemura N, et al. Extracorporeal membrane oxygenation as a bridge to lung transplant: midterm outcomes. Ann Thorac Surg 2011;92(4): 1226-1231; discussion 1231-1232.

18. Reeb J, Falcoz PE, Santelmo N, Massard G. Double lumen bi-cava cannula for veno-venous extracorporeal membrane oxygenation as bridge to lung transplantation in non-intubated patient. Interact Cardiovasc Thorac Surg 2011;14(1):125-127.

19. Rehder KJ, Turner DA, Cheifetz IM. Use of extracorporeal life support in adults with severe acute respiratory failure. Expert Rev Respir Med 2011;5(5):627-633.

20. Wang D, Zhou X, Liu X, Sidor B, Lynch J, Zwischenberger JB. Wang-Zwische double lumen cannula-toward a percutaneous and ambulatory paracorporeal artificial lung. ASAIO J 2008;54(6): 606-611.

21. Garcia JP, Iacono A, Kon ZN, Griffith BP. Ambulatory extracorporeal membrane oxygenation: a new approach for bridge-tolung transplantation. J Thorac Cardiovasc Surg 2010;139(6): e137-139.

22. Mangi AA, Mason DP, Yun JJ, Murthy SC, Pettersson GB. Bridge to lung transplantation using short-term ambulatory extracorporeal membrane oxygenation. J Thorac Cardiovasc Surg 2010;140(3): 713-715.

23. Latronico N, Bolton CF. Critical illness polyneuropathy and myopathy: a major cause of muscle weakness and paralysis. Lancet Neurol 2011;10(10):931-941.

24. Misak CJ. ICU-acquired weakness: obstacles and interventions for rehabilitation. Am J Respir Crit Care Med 2011;183(7):845846 .

25. Morris PE, Griffin L, Berry M, Thompson C, Hite RD, Winkelman $\mathrm{C}$, et al. Receiving early mobility during an intensive care unit admission is a predictor of improved outcomes in acute respiratory failure. Am J Med Sci 2011;341(5):373-377.

26. Schweickert WD, Pohlman MC, Pohlman AS, Nigos C, Pawlik AJ, Esbrook CL, et al. Early physical and occupational therapy in mechanically ventilated, critically ill patients: a randomised controlled trial. Lancet 2009;373(9678):1874-1882.

27. Hankinson JL, Odencrantz JR, Fedan KB. Spirometric reference values from a sample of the general US population. Am J Respir Crit Care Med 1999;159(1):179-187.

28. Vermeijden JW, Zijlstra JG, Erasmus ME, van der Bij W, Verschuuren EA. Lung transplantation for ventilator-dependent respiratory failure. J Heart Lung Transplant 2009;28(4):347-351.

29. Orens JB, Estenne M, Arcasoy S, Conte JV, Corris P, Egan JJ, et al. International guidelines for the selection of lung transplant candidates: 2006 update: a consensus report from the Pulmonary Scientific Council of the International Society for Heart and Lung Transplantation. J Heart Lung Transplant 2006;25(7): 745-755.

30. Hämmäinen P. Re: Use of extracorporeal membrane oxygenation as a bridge to primary lung transplant: 3 consecutive, successful cases 


\section{Active Rehabilitation During Extracorporeal Membrane Oxygenation}

and a review of the literature. J Heart Lung Transplant 2008;27(10): 1186.

31. Baz MA, Palmer SM, Staples ED, Greer DG, Tapson VF, Davis DD. Lung transplantation after long-term mechanical ventilation: results and 1-year follow-up. Chest 2001;119(1):224-227.

32. Burton CM, Milman N, Carlsen J, Arendrup H, Eliasen K, Andersen $\mathrm{CB}$, et al. The Copenhagen National Lung Transplant Group: survival after single lung, double lung, and heart-lung transplantation. J Heart Lung Transplant 2005;24(11):1834-1843.

33. Kreisel D, Krupnick AS, Puri V, Guthrie TJ, Trulock EP, Meyers BF, et al. Short- and long-term outcomes of 1000 adult lung transplant recipients at a single center. J Thorac Cardiovasc Surg 2011;141(1): 215-222.

34. Hsu HH, Chen JS, Ko WJ, Huang SC, Kuo SW, Huang PM, et al. Short-term outcomes of cadaveric lung transplantation in ventilatordependent patients. Crit Care 2009;13(4):R129.

35. Hadjiliadis D, Steele MP, Govert JA, Davis RD, Palmer SM. Outcome of lung transplant patients admitted to the medical ICU. Chest 2004;125(3): 1040-1045.

36. Iacono A, Groves S, Garcia J, Griffith B. Lung transplantation following 107 days of extracorporeal membrane oxygenation. Eur J Cardiothorac Surg 2010;37(4):969-971.

This article is approved for Continuing Respiratory Care Education credit. For information and to obtain your CRCE

(free to AARC members) visit 